\title{
A comparative study between a late-ripening mutant of citrus and its original line in fruit coloration, sugar and acid metabolism at all fruit maturation stage
}

\author{
Yonghua Qin ${ }^{1,2}$, Guyu Li ${ }^{1,2}$, Lu Wang ${ }^{1,2}$, Jaime A Teixeira Da Silva ${ }^{3}$, Zixing Ye ${ }^{2}$, Qirui Feng ${ }^{2}$ \\ and Guibing $\mathrm{Hu}^{1,2, \star}$ \\ 1 State Key Laboratory for Conservation and Utilization of Subtropical Agro-bioresources, College of Horticulture, South China Agricultural \\ University, Guangzhou 510642, China \\ 2 Key Laboratory of Biology and Genetic Improvement of Horticultural Crops-South China of Ministry of Agriculture, College of Horticulture, \\ South China Agricultural University, Guangzhou 510642, China \\ 3 P.O. Box 7, Miki-cho Post office, Ikenobe 3011-2, Kagawa-ken, 761-0799 Japan
}

Received 7 April 2014 - Accepted 4 August 2014

\begin{abstract}
Introduction. Fruit color is one of the important external traits that can be used to judge fruit maturation time in citrus. Mutants with different color are useful to study the regulating mechanism of color development. Materials and methods. A new seedless and late-maturing cultivar, 'Huawan Wuzishatangju' (HWWZSTJ) (Citrus reticulata Blanco), was selected from 'Wuzishatangju' (WZSTJ) through spontaneous bud mutation. Differences in fruit coloration, sugar and acidity contents of the two cultivars were investigated throughout fruit ripening. Results and discussion. Fruit of HWWZSTJ matured in late January to early February, more than 30 days later than WZSTJ. Results from RAPD analysis showed that HWWZSTJ originated from genetic mutation. The chlorophyll, carotenoid, total soluble solid (TSS) and total titratable acidity (TTA) contents of HWWZSTJ were affected by the mutation. Chlorophyll content in peel of HWWZSTJ was significantly higher than that of WZSTJ from November to mid-January while carotenoid content of HWWZSTJ peel was significantly higher than that of WZSTJ throughout fruit maturation. TTA content in HWWZSTJ was significantly higher than that in WZSTJ during early fruit ripening (from Nov. 29 to Dec. 9). Highest TSS $(14.1 \%)$ was detected in the flesh of WZSTJ in mid-January compared to highest TSS (14.4\%) of HWWZSTJ in early February. Conclusion. The mutation in HWWZSTJ detected by RAPD analysis, affected fruit coloration, sugar and acid metabolism, and might be responsible for other late-ripening phenotypes.
\end{abstract}

Keywords: China / Citrus reticulata / selection criteria / biological properties / somatic mutation / late-maturation

Résumé - Étude comparative entre un mutant tardif d'agrume et sa lignée d'origine d'après la coloration du fruit, le métabolisme des sucres et des acides à chaque étape de maturation du fruit. Introduction. La couleur du fruit est un des caractères externes importants qui peut être utilisé pour juger la durée de maturation du fruit chez les agrumes. Les mutants de couleur sont utiles pour étudier le mécanisme régulateur de progression de la coloration. Matériel et méthodes. Une nouvelle variété cultivée sans pépins et mûrissant tardivement, 'Huawan Wuzishatangju' (HWWZSTJ) (Citrus reticulata Blanco) a été retenue, dérivée de 'Wuzishatangju' (WZSTJ) par mutation embryonnaire spontanée. Les différences de coloration du fruit, la teneur en sucres et le taux d'acidité des deux variétés cultivées ont été examinés tout au long de la maturation du fruit. Résultats et discussion. Les fruits de HWWZSTJ ont mûri de fin janvier à début février, plus de 30 jours plus tard que ceux de WZSTJ. Les résultats d'analyse RAPD ont montré que HWWZSTJ était un mutant génétique. Les teneurs en chlorophylle, caroténoïdes, sucres solubles totaux (TSS) et acidité titrable totale (TTA) de HWWZSTJ ont été affectés par la mutation. La teneur en chlorophylle dans la pelure de HWWZSTJ était significativement plus élevée que celle de WZSTJ de novembre à la mi-janvier de l'année suivante. De même, la teneur en caroténoïdes de cette même pelure de HWWZSTJ était significativement plus élevée que celle de WZSTJ tout au long de la maturation du fruit. Le taux d'acidité (TTA) de HWWZSTJ était significativement plus élevé que celui de WZSTJ pendant la phase précoce de maturation du fruit (du 29 novembre au 9 décembre). Les plus forts taux de sucres $(14.1 \%)$ ont été détectés dans la chair de WZSTJ à la mi-janvier, alors que pour HWWZSTJ, les plus forts TSS (14.4\%) sont apparus début février. Conclusion. La mutation dans HWWZSTJ détectée par analyse RAPD a affecté la coloration du fruit, le métabolisme des sucres et des acides, et pourrait être responsable des phénotypes mûrissant tardivement.

Mots clés : Chine / Citrus reticulata / critères de sélection / propriétés biologiques / mutation somatique / retard de maturation

\footnotetext{
^ Corresponding author: guibing@scau.edu.cn
} 


\section{Introduction}

Citrus, one of the most economically important fruit crops, is commercially produced in more than 140 countries. The primary producers are Brazil, the Mediterranean Basin, the United States and China [1]. In the past decade world's citrus production has increased steadily to meet growing international demands. To date, citrus fruits combined ranks first among fruit crops in international fruit trade with respect to area planted and production. The total area harvested of citrus exceeds 8.8 million ha, with an annual output of over 130 million tons [2]. Since citrus production makes a significant contribution to the economy of citrusgrowing countries [2], governments in these countries are now paying much more attention to citrus germplasm collection and varietal selection.

Citrus is among the most difficult plants to improve through traditional breeding approaches due to its high genetic heterozygosity, long juvenility, nucellar embryo interference, and self-sterility or incompatibility of certain species [1]. Bud mutation selection has been widely used for creating novel cultivars in vegetatively propagated plants leading to the development of new varieties [3]. Bud mutations often arise since Citrus cultivars are maintained by vegetative propagation [4]. Most excellent cultivars of clémentine mandarin (Citrus clementina Hort. ex Tan.), Satsuma mandarin (C. unshiu Marc), and sweet orange [C. sinensis (L.) Osbeck] have been obtained through bud mutation selection [4-6]. Therefore, improvement in citrus is largely dependent on the result of bud mutation events.

'Wuzishatangju' (WZSTJ) mandarin (C. reticulata Blanco) is an excellent cultivar derived from a bud sport of a seedy cultivar 'Shatangju' which was found in Guangdong province in the 1980s [7]. It is seedless, very tasty and easy to peel, and has become one of the most popular mandarin cultivars in China [7]. Currently, the total area of WZSTJ is estimated to be over 200,000 ha in Guangdong and Guangxi provinces. WZSTJ fruit matures in late December to early January and its shelf life is 1-2 weeks at room temperature. WZSTJ is considered to be one of the most difficult mandarin cultivars to store due to its thin peel and high total soluble solid (TSS) content. WZSTJ is not suitable for juice production because of its relatively low juice content. Therefore, breeding an early or late-maturing variety is essential to extend its shelf life, meet the needs of consumers, and increase revenue for the majority of growers. In this study, 'Huawan Wuzishatangju' (HWWZSTJ) a new seedless and late-maturing mandarin cultivar, was selected from WZSTJ through natural bud mutation selection. Changes of pigments, and TSS and total titratable acidity (TTA) contents were analyzed at all fruit maturation stages of the late-maturing mutant HWWZSTJ and its original cultivar WZSTJ. The late-maturing mechanism of HWWZSTJ is also discussed.

\section{Materials and methods}

\subsection{Plant materials}

'Wuzishatangju' (WZSTJ) and 'Huawan Wuzishatangju' (HWWZSTJ) mandarins were planted in an orchard of South
China Agricultural University. Six-year-old trees of each cultivar were used in this experiment. Twenty fruit were separately collected from three trees at 10-day intervals from Nov. 29 to Feb. 7 to determine peel chlorophyll and carotenoid contents TSS and TTA. Sixty fruit of each cultivar were picked randomly at commercial maturity to assess fruit quality.

\subsection{Process of selection}

In 2007, a novel late-maturing tree that resulted from a bud mutation was found in a WZSTJ orchard in Min'an village, Fogang County, Guangdong Province, China. Asexual propagation of the mutant was conducted at three locations, namely Fogang County, Guangdong Province Cangwu Country, Guangxi Province and Guangzhou City, Guangdong Province. It was determined that the characteristics of the mutations were genetically stable and could reproduce trueto-type clones in successive generations. The mutation was registered and released as a new variety with the name of HWWZSTJ by the Guangdong Provincial Crops Variety Approval Committee on January 10, 2013.

\subsection{Observation of botanical and biological characteristics}

The stem, leaf, flower, fruit, and yield characteristics were investigated according to descriptors and data standards for Citrus spp. [8].

\subsection{Fruit quality assessments}

Four taste components and five other characteristics related to fruit quality were assessed using 60 fruit picked randomly from three trees (20 fruit per tree) at commercial maturity in the orchard of South China Agricultural University. The taste components included TSS, total sugar (TS), TTA, and vitamin C contents, which were determined by the Supervision and Testing Center for Vegetables and Fruits Quality, Ministry of Agriculture, Guangzhou. The five other fruit characteristics were weight per fruit, fruit shape index, peel thickness, seed number and edible rate (ER). Fruit weight seed number and ER were recorded as the average values of 20 fruits sampled at random from each tree. ER was calculated as follows:

ER $(\%)=[($ fruit weight - peel weight - seed weight $) /$ fruit weight $] \times 100$.

\subsection{RAPD analysis}

Genomic DNA was extracted from young leaves using a CTAB method [9]. A total of 1196 random amplified polymorphic DNA (RAPD) primers were used to detect the genetic variations between HWWZSTJ and WZSTJ according to the protocol of Qin et al [10]. The $25.0 \mu \mathrm{L}$ of reaction volume contained 1.2 -fold $10 \times$ buffer $\left(\mathrm{Mg}^{2+}\right)$, $0.2 \mathrm{mM}$ dNTP (Sangon Biotech, Shanghai), $0.2 \mu \mathrm{M}$ primer (Sangon Biotech, Shanghai), 1.2 U rTaq (TaKaRa, Dalian, P. R. China), $0.8 \mathrm{ng} \mu \mathrm{L}^{-1}$ DNA template. PCR products were examined by ethidium bromide-staining $1.5 \%(\mathrm{w} / \mathrm{v})$ agarose gel electrophoresis. 


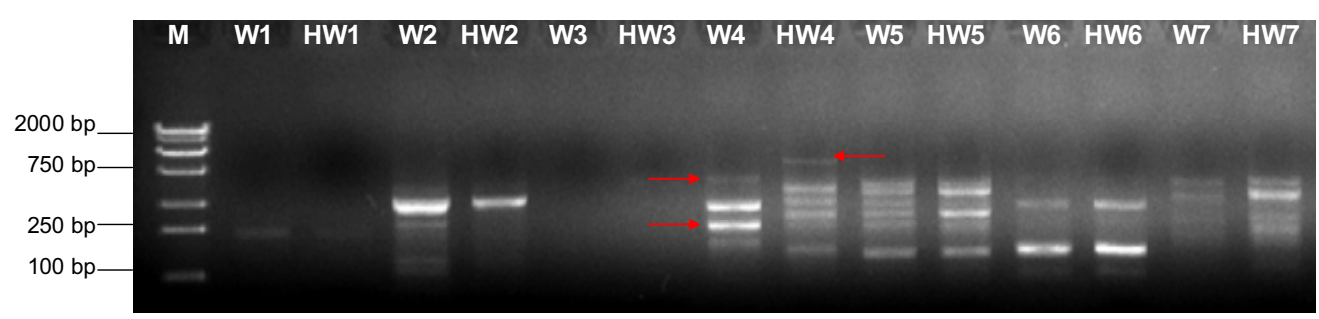

Figure 1. Partial RAPD results of Wuzishatangju (W1-7) and Huwan Wuzishatangju (HW1-7). M, DL2000 DNA marker (TaKaRa); Lanes 1-7, PCR products using different RAPD primers.

\subsection{Peel color measurement}

Contents of peel chlorophyll and carotenoids were measured according to the method described by Arnon [11]. Peel color measurements were made on 20 fruit samples immediately after picking. $L^{*}, a^{*}$, and $b^{*}$ values were measured at the equator on opposite cheeks of the fruit with a Konica Minolta CR-10 Chroma Meter (Minolta, Japan). The lightness coefficient $L^{*}$ represents brightness and darkness, $a^{*}$ value represents greenish and redness as the value increases from negative to positive, and $b^{*}$ represents bluish and yellowish. The Chroma value was calculated according to the following equation: $\Delta \mathrm{C}^{*}{ }_{a b}=\left(\Delta a^{* 2}+\Delta b^{* 2}\right)^{0.5}[12]$.

\subsection{Determination of total soluble solids and titratable acidity}

TSS was assessed from filtered juice from whole flesh tissues using a portable refractometer (PR-32 $\alpha$, Japan). A portion of the filtered juice was used to determine TTA following the procedure of Padda et al. [12].

\subsection{Statistical analyses}

Statistical analyses were performed using MS Excel and SPSS 18.0 software Differences of compared sets were considered significant using LSD test at $P \leqslant 0.05$.

\section{Results}

\subsection{Botanical and biological characteristics}

The new citrus cultivar HWWZSTJ had the same botanical characteristics as its original cultivar WZSTJ after observation at three locations for five consecutive years. Fruit of WZSTJ matured in late December to early January of the following year while fruit of HWWZSTJ matured in late January to early February of the following year, more than 30 days later than WZSTJ.
Table I. Fruit characteristics of 'Huawan Wuzishatangju' and 'Wuzishatangju'.

\begin{tabular}{lcc}
\hline \multirow{2}{*}{ Fruit characteristics } & \multicolumn{2}{c}{ Cultivars } \\
\cline { 2 - 3 } & $\begin{array}{c}\text { Huawan } \\
\text { Wuzishatangju }\end{array}$ & Wuzishatangju \\
\hline Weight per fruit (g) & $45.4 \mathrm{a}$ & $43.4 \mathrm{a}$ \\
Fruit shape index & $0.8 \mathrm{a}$ & $0.8 \mathrm{a}$ \\
Peel thickness (mm) & $2.0 \mathrm{a}$ & $2.3 \mathrm{a}$ \\
Number of seeds & $0.6 \mathrm{a}$ & $0.7 \mathrm{a}$ \\
Total soluble solids (\%) & $14.4 \mathrm{a}$ & $14.1 \mathrm{a}$ \\
Total sugar $(\%)$ & $11.4 \mathrm{a}$ & $10.3 \mathrm{a}$ \\
Titratable acidity (\%) & $0.38 \mathrm{a}$ & $0.29 \mathrm{a}$ \\
Vitamin C & $23.2 \mathrm{a}$ & $14.5 \mathrm{~b}$ \\
(mg 100 g & & \\
Edible rate (\%) $(\%$ weight) & $79.9 \mathrm{a}$ & $73.6 \mathrm{~b}$ \\
\hline
\end{tabular}

Different letters within the same row indicate significant differences using LSD test at $P \leqslant 0.05$. Sixty fruit of Huawan Wuzishatangju and Wuzishatangju were picked randomly from three trees to assess their fruit quality at commercial maturity (Wuzishatangju was picked on Jan. 8, 2011 while Huawan Wuzishatangju was picked on Feb. 7, 2011).

\subsection{Fruit quality}

Mature fruit of HWWZSTJ is similar in quality to that of WZSTJ with few seeds present (less than 1.0 per fruit) ( $t a-$ ble I). The average size of HWWZSTJ fruit was $5.0 \mathrm{~cm}$ on the equatorial diameter and $4.0 \mathrm{~cm}$ on the polar diameter with an oblate fruit shape. The average weight of HWWZSTJ fruit was $45.4 \mathrm{~g}$. HWWZSTJ fruit has an easy to peel skin, which is $2.0 \mathrm{~mm}$ thick. The flesh is orange, sweet, fibreless and crisp, with an average TSS of $14.4 \%$ (table I). Vitamin C content and ER of HWWZSTJ are $23.2 \mathrm{mg} 100 \mathrm{~g}^{-1}$ fresh weight and $79.9 \%$, respectively, which is significantly higher than that of WZSTJ (table I).

\subsection{RAPD analysis of both cultivars}

Genetic differences between HWWZSTJ and WZSTJ were assessed by RAPD analysis. Three distinct fragments (shown by arrows) were obtained using AD16 (AACGGGCGTC) primers (figure 1) indicating that HWWZSTJ originated from a genetic mutation. 


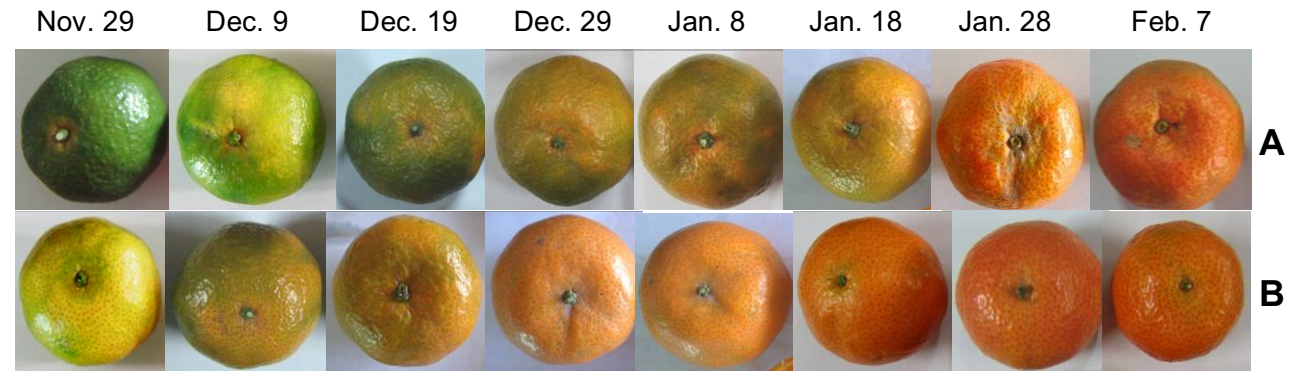

Figure 2. Changes in fruit color of HWWZSTJ and WZSTJ during all fruit maturation stages. A, Huawan Wuzishatangju; B, Wuzishatangju. A color figure is available at www.fruits-journal.org

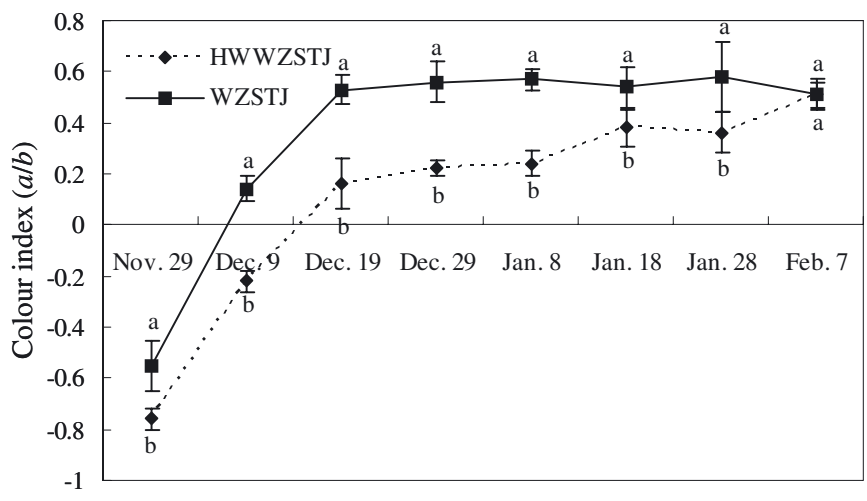

Figure 3. Changes in color index of HWWZSTJ and WZSTJ during all fruit maturation stages. Bars represent the standard error $(n=3)$. Different letters indicate significant differences between treatments using LSD test at $P \leqslant 0.05$.

\subsection{Changes in fruit color of both cultivars}

HWWZSTJ showed a delay in peel coloration compared with WZSTJ by the end of November (figure 2). The onset of peel coloration in WZSTJ started in late November and full coloration was complete by mid-December. For HWWZSTJ peel coloration started in mid-December whith full coloration in late January. HWWZSTJ retained good internal fruit quality as judged by TSS, TS, TTA, and vitamin C contents until early March. There was a significant difference in color index $(a / b$ ratio) between HWWZ STJ and WZSTJ during fruit ripening. The color break $(a / b=0)$ of HWWZSTJ was about two weeks later than that of its original cultivar WZSTJ (figure 3).

\subsection{Changes in chlorophyll and carotenoid content in the peel of both cultivars}

Chlorophyll $a$ and Chlorophyll $b$ showed the same decreasing trend in both cultivars over all fruit maturation stages (figures $4 A, 4 B$ ). Significant degradation of chlorophyll in WZSTJ occurred from early to mid-December but the process in HWWZSTJ was in early January. The chlorophyll content in the peel of HWWZSTJ was significantly higher than that of WZSTJ from November to mid-January. Carotenoid content of the HWWZSTJ peel was significant higher than that of the WZSTJ peel throughout fruit maturation. Carotenoid content of the HWWZSTJ peel increased gradually throughout all fruit maturation stages but in WZSTJ, it increased from Nov 29 to Jan 8 and decreased when fruit was fully mature.

\subsection{Changes in TSS and TTA in the flesh of both cultivars}

The TSS content in WZSTJ increased gradually during the early ripening period (from Nov 29 to Jan 18) and decreased during the late ripening period (from Jan 18 to Feb7) (figure $5 A$ ). The highest TSS content $(14.1 \%)$ in WZSTJ was detected on Jan 18 and decreased significantly thereafter. TSS in HWWZSTJ increased gradually over the entire sampling period with the highest TSS content (14.4\%) detected on Feb 7. Differences in TTA content were observed for both cultivars during fruit maturation (figure 5B). TTA content decreased significantly during fruit ripening of the both cultivars. TTA content in HWWZSTJ was significantly higher than in WZSTJ during early fruit ripening (from Nov 29 to Dec 9). However, no significant difference in the TSS/TTA ratio was detected between HWWZSTJ and WZSTJ except on January 8 .

\section{Discussion}

China is one of the leading citrusproducing countries in the world with an estimated production exceeding 30 million tonnes in 2012 [2]. Currently, the citrus harvest season is mainly in November and December which cannot provide high-quality fresh citrus all year round. To meet this challenge, efforts to improve citrus are increasingly turning to the breeding of early or late maturing varieties to expand the citrus season for the fresh-fruit market [4]. The majority of new citrus varieties originate from the selection of bud mutation, the most common method for developing new citrus varieties, particularly those with a change in the timing of fruit maturity [4,5]. Currently, several late maturing Citrus cultivars such as 'Fengwan' navel orange ( $C$ sinensis Osbeck) [13], 'Mingliu 

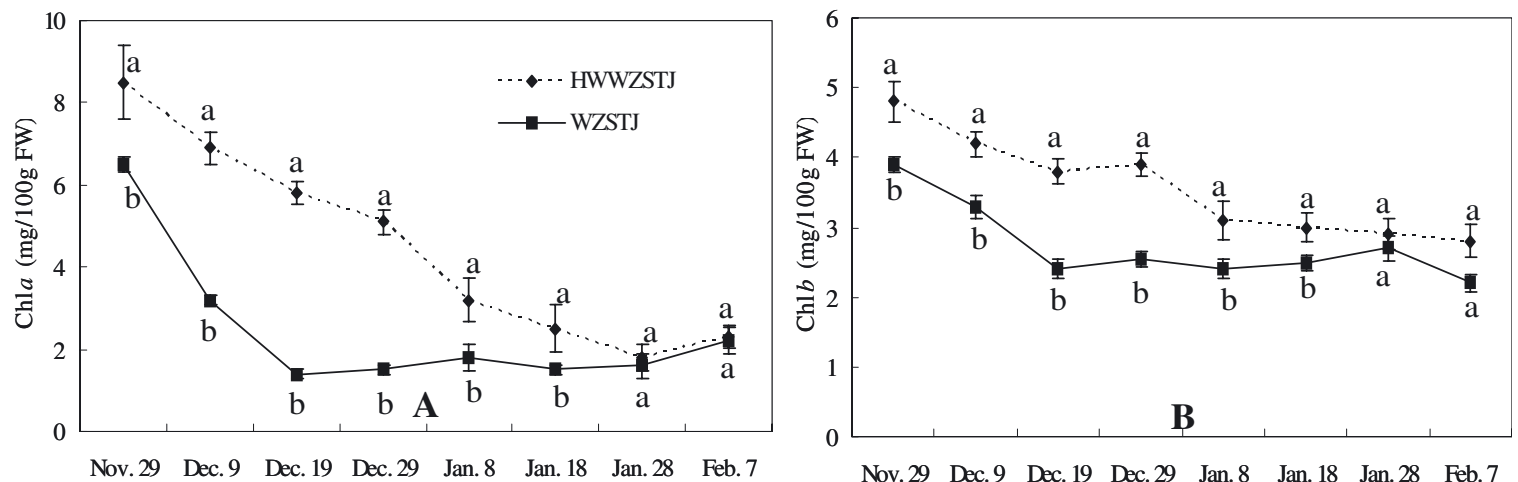

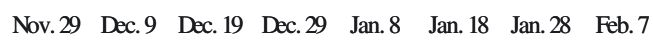

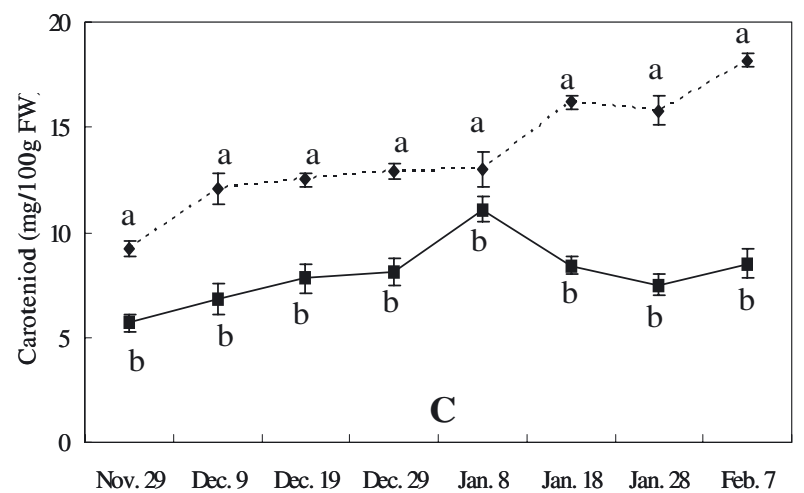

Figure 4. Changes in chl $a$ (A), chl $b$ (B) and carotenoid (C) contents of HWWZSTJ and WZSTJ during all fruit maturation stages. Bars represent the standard error $(n=3)$. Different letters indicate significant differences between treatments using LSD test at $P \leqslant 0.05$.
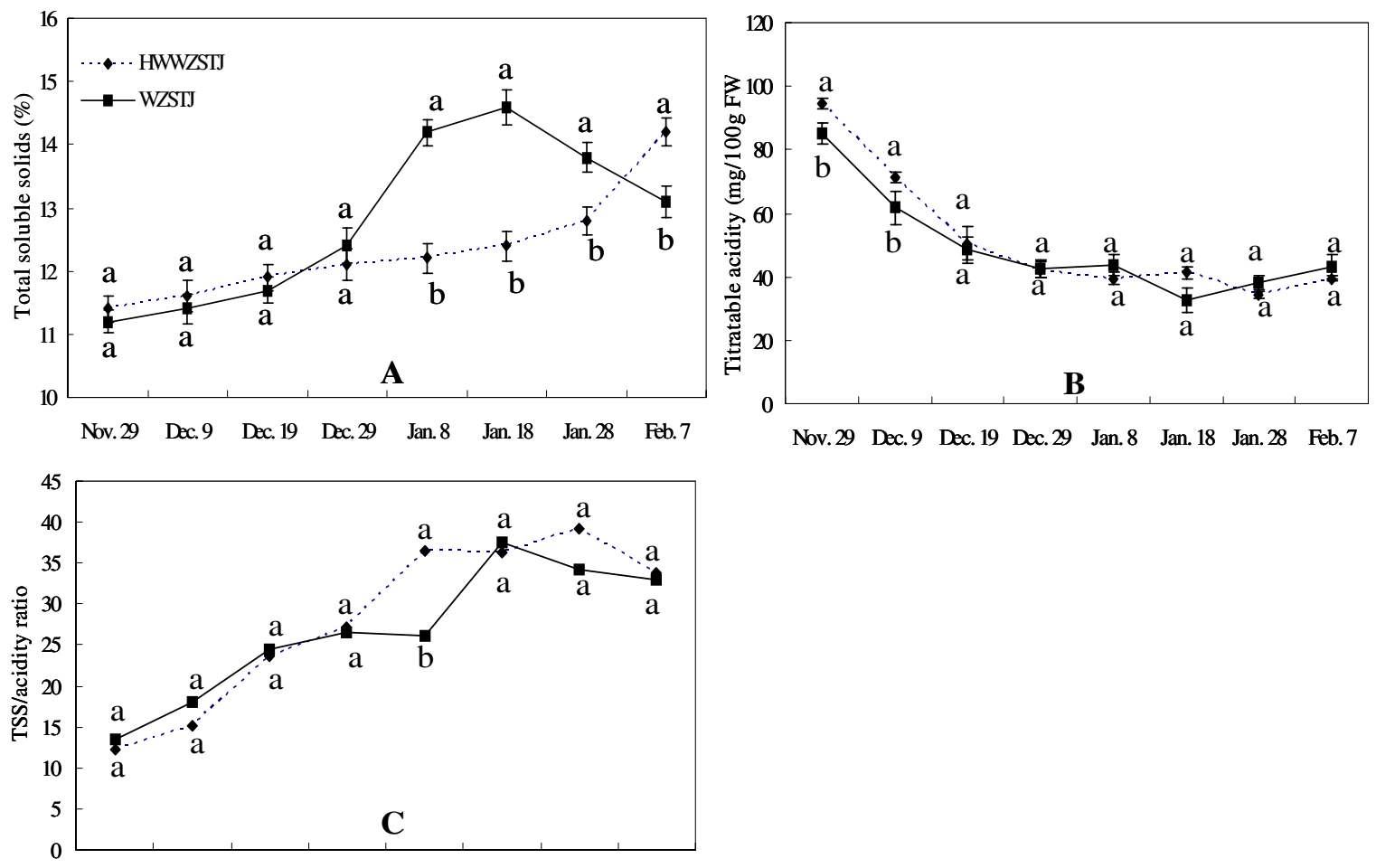



Figure 5. Changes in total soluble solids (A), titratable acidity (B) and TSS/acidity ratio (C) of HWWZSTJ and WZSTJ during all fruit maturation stages. Bars represent the standard error $(n=3)$. Different letters indicate significant differences between treatments using LSD test at $P \leqslant 0.05$. 
Tianju' mandarin (C reticulata Blanco) [14], 'Murcott' mandarin [15] and 'Yuenong Wanju' (C reticulata) [16] have been obtained through the selection of bud mutations. In this study, a novel late-maturing mandarin cultivar HWWZSTJ was selected from WZSTJ, which originated from a bud mutation. Compared to WZSTJ, the mature period of HWWZSTJ was more than $30 \mathrm{~d}$ later. RAPD results (figure 1) indicated that HWWZSTJ was caused by genetic mutation(s). Therefore, the two cultivars provide excellent material for studying the mechanism of color regulation in citrus fruit ripening.

Fruit ripening is a complex, genetically programmed process involving multiple physiological and biochemical changes [17-19]. During citrus fruit development, a massive accumulation of carotenoids and sugar occurs concomitantly with the degradation of chlorophyll and acidity [19]. Peel color is one of the important external traits that can be used to judge fruit maturation time in citrus. Carotenoids are the main pigments responsible for the attractive color of the peel and pulp of citrus fruit and greatly contribute to their nutritional and antioxidant value [20]. Chlorophyll and carotenoid contents are responsible for the color of the developing citrus fruit and as fruit ripening progresses, fruit color changes from green to orange as chlorophylls are degraded and carotenoids accumulate [13]. Early or late coloration is correlated with the speed of chlorophyll degradation and carotenoid accumulation in citrus peel [21]. In the present study, intense color changes that occurred during fruit ripening arose from the degradation of chlorophyll and the accumulation of carotenoids. The greento-orange color change typical of ripening HWWZSTJ fruit is largely due to chlorophyll degradation and carotenoid accumulation. In this study, higher chlorophyll and carotenoid contents were detected in the peel of both WZSTJ and HWWZSTJ during all fruit maturation stages These results suggest that color transition in the peel of HWWZSTJ was approximately 30 days later than the peel of WZSTJ, which was mainly due to the slow degradation of chlorophyll and the accumulation of carotenoids during fruit ripening. Similar results were also reported in fruit ripening of Fengwan, a late-maturing mutant and its original cultivar Fengjie 72-1 of navel orange.

The TSS:TTA ratio is used as a legal standard for oranges because both parameters are closely associated with internal fruit quality [23]. The accumulation of sugars and the drop in acidity level are characteristics of citrus fruit ripening [13, $21,23,24]$. In our study, the TSS content gradually increased and TTA content decreased during fruit maturation (figure $5 \mathrm{~A}$ and figure $5 B$ ). TSS in WZSTJ increased gradually before fruit ripening and decreased thereafter while TSS in HWWZSTJ increased gradually during the whole sampling period. TSS in WZSTJ was significantly higher than that in HWWZSTJ from mid- to late-January but was lower after early February (figure 5A).

Fruit ripening is a complex process involving changes in color, aroma, metabolism of sugars and organic acids, texture and softening [25-28]. All biochemical and physiological changes that take place during fruit ripening are driven by the coordinated expression of fruit ripening-related genes [25-28].

Further studies such as gene mutation and gene expression of all genes involved in pigment metabolism of HWWZSTJ are under way.

\section{Conclusion}

Late maturity of a mutant variety HWWZSTJ which is associated with the late triggering of fruit maturation biochemical pathways is clearly shown in the present study. Further studies such as gene mutation and gene expression of all genes involved in pigment metabolism of HWWZSTJ are under way.

Acknowledgements. This work was supported by the Science and Technology Planning Project of Guangdong Province, China (2010B020305007), Key Laboratory of Innovation and Utilization for Germplasm Resources in Horticultural Crops in Southern China of Guangdong Higher Education Institutes, the South China Agricultural University (No. KBL11008) and the "211" Construction Fund for Key Subjects of College of Horticulture, South China Agricultural University.

\section{References}

[1] Ladaniya M.S. (ed.), Citrus fruit: biology, technology and evaluation, Amsterdam: Elsevier, 2008.

[2] FAOSTAT. http://faostat.fao.org/site/567/DesktopDefault.aspx? PageID\$=\$567\#ancor, 2014.

[3] Marcotrigiano M., Chimeras and variegation: patterns of deceit, HortSci. 32 (1997) 773-784.

[4] Zhang M., Deng X.X., Advances in research of citrus cultivars selected by bud mutation and the mechanism of formation of mutated characteristics, J. Fruit Sci. 23 (2006) 871-876.

[5] Asins M.J., Monforte A.J., Mestre P.F., Carbonell E.A., Citrus and Prunus Copia-like retrotransposons, Theor. Appl. Genet. 99 (1999) 503-510.

[6] Liu Y.Z., Deng X.X., Citrus breeding and genetics in China, Asian Aust. J. Plant Sci. Biotechnol. 1 (2007) 23-28.

[7] Ye Z.X., Zeng T., Xu, J.K., Luo Z.D., Hu G.B., Zhang Z.Q., Ji Z.L., Chen Y.C., Chen G.L., Chen L.X., Lin S.Q., Wuzishatangju, a new mandarin cultivar, J. Fruit Sci. 23 (2006) $149-150$.

[8] Jiang D., Gong G.Z., Descriptors and data standard for citrus (Citrus spp.), China Agricultural Press, 2006.

[9] Xiong G.M., Liang G.L., Yan Y., Xiang S.Q., Wu Q., Li X.Q., Jiang D., DNA extraction method for AFLP analysis in Citrus, J. Fruit Sci. 19 (2002) 267-268.

[10] Qin Y.H., Hu H.G., Ye Z.X., Lin S.Q., Miao H.X., Zhang C.Y., Hu, G.B., Identification of progenies derived from sexual hybridization of citrus using RAPD molecular marker, Acta Hortic. 894 (2011) 123-132.

[11] Arnon D.I., Copper enzymes in isolated chloroplasts. Polyphenoxidase in Beta vulgaris, Plant Physiol. 24 (1949) 15.

[12] Padda M.S., Do Amarante C.V.T., Garcia R.M., Slaughter D.C., Mitcham E.J., Methods to analyze physico-chemical changes during mango ripening: A multivariate approach, Postharvest Biol. Tec. 62 (2011) 267-274.

[13] Liu Y.Z., Tang P., Tao N.G., Xuan X., Peng S.H., Deng X.X., Xiang K.S., Huang R.H., Fruit coloration difference between Fengwan, a late-maturing mutant and its original cultivar Fengjie 72-1 of navel orange (Citrus sinensis Osbeck), J. Plant Physiol. Mol. Biol. 32 (2006) 31-36.

[14] Zeng J.W., Peng C.J., Yi G.J., Du G.X., Zhang S.P., Feng C.T., Huo H.Q., Zhong Y., Zhou B.R., Huang Y.H., A new late ripening citrus variety 'Mingliu Tianju', Acta Hortic. Sin. 33 (2006) 1164-1164. 
[15] Yu Y.B., Lin B., Wang Q., Chen Y., Lai C.C., Xie H.G., Selection of a late-ripening, high quality orange, 'Murcott', Fujian J. Agric. Sci. 25 (2010) 167-169.

[16] Zhou B.R., Tan K.C., Chen Y.H., Zhong Y., Luo W.L., Zeng J.W., Zhong G.Y., Jiang B., Ji Q.H., Huang H.Y., Zhou C.A., A new citrus cultivar 'Yuenong Wanju', Acta Hortic. Sin. 40 (2013) 997-998.

[17] Patel PR, Gol NB, Rao TVR, Physiochemical changes in sunberry (Physalis minima L.) fruit during growth and ripening, Fruits 66 (2011) 37-46.

[18] Pongener A, Sagar V, Pal RK, Aarey R, Sharma RR, Singh SK., Physiological and quality changes during postharvest ripening of purple passion fruit (Passiflora edulis Sims), Fruits 69 (2014) 19-30.

[19] Giovannoni J., Molecular biology of fruit maturation and ripening, Ann. Rev. Plant Physiol. Plant Mol. Biol. 52 (2001) 725-749.

[20] Alquézar B., Rodrigo M.J., Zacarías L., Carotenoid biosynthesis and its regulation in citrus fruits, Tree Forestry Sci. Biotechnol. 2 (2008) 23-35.

[21] Baldwin E.A., Citrus fruit in biochemistry of fruit ripening, Edited by Seymour G.B., Taylor J.E., Tuker G.A., Chapman \& Hall, London, 1993.
[22] Pangborn R., Relative taste intensities of selected sugars and organic acids, Food Sci. 28 (1963) 726-733.

[23] Luo A.C., Yang X.H., Deng Y.Y., Li C.F., Xiang K.S., Li D.G., Organic acid concentrations and the relative enzymatic changes during the development of citrus fruits, Sci. Agric. Sin. 36 (2003) 941-944.

[24] Ou S.H., Mai S.Q., Mei Z.M., Mo J.S., Chen Y.C., Liu S.Q., Gan H.F., Wang M.Z., Deng G.Z., Chen, G.F. Elucidation of mechanism of ripening in late-ripening variety of Jiaogan mandarins fruit, Guangxi Agric. Sci. 40 (2009) 889-892.

[25] Kato M., Ikoma Y., Matsumoto H., Sugiura M., Hyodo H., Yano M., Accumulation of carotenoids and expression of carotenoid biosynthetic genes during maturation in citrus fruit, Plant Physiol. 134 (2004) 824-837.

[26] Liu Y.Z., Liu Q., Xiong J.J., Deng X.X., Difference of a citrus late-ripening mutant (Citrus sinensis) from its parental line in sugar and acid metabolism at the fruit ripening stage, Sci. China Ser. C-Life Sci 50 (2007) 511-517

[27] Bouzayen M., Latche A., Nath P., Pech J.C., Plant developmental biology- biotechnological perspectives, Springer, Berlin Heidelberg, 2010.

[28] Singh Z., Singh R.K., Sane V.A. Nath P. Mango-postharvest biology and biotechnology, Crit Rev Plant Sci 32 (2013) 217-236.

Cite this article as: Yonghua Qin, Guyu Li, Lu Wang, Jaime A Teixeira Da Silva, Zixing Ye, Qirui Feng, Guibing Hu-1.2mm. A comparative study between a late-ripening mutant of citrus and its original line in fruit coloration, sugar and acid metabolism at all fruit maturation stage$1.2 \mathrm{~mm}$. Fruits 70 (2015) 5-11. 